\title{
Collaborative Assessment of Potential Value Generation in Development Projects
}

\author{
Ingo Westphal ${ }^{1}$, Jens Eschenbächer ${ }^{2}$, and Donatella Vedovato ${ }^{3}$ \\ ${ }^{1}$ BIBA - Bremer Institut für Produktion und Logistik GmbH, Hochschulring 20, \\ 28359 Bremen, Germany \\ win@biba. uni-bremen. de \\ ${ }^{2}$ BIBA \\ esc@biba.uni-bremen.de \\ ${ }^{3}$ Venice International University, 30122 Venezia, Italy \\ donatella.vedovato@univiu.org
}

\begin{abstract}
Today development projects, in particular the development of complex products, are in many cases no task of a single company anymore. They usually require the active involvement of suppliers and sometimes even of customers. Since all involved partners have to invest time and money in the development activities it has to be ensured that the new product generates concrete value for the potential customers so that there is an adequate return on investment. One challenge is to assess the potential value generation in the early development phases when only a few basic specifications are available. This challenge becomes even bigger when contributions of different partners and customers are required. In this paper the assessment of potential value generation is regarded as a collaborative process and it is analyzed which collaboration capabilities are required in this process. The objective of the paper is to suggest an approach for a collaborative assessment of potential value generation in early development phases that considers the requirements upon collaboration capabilities of the different involved partners. In research and development projects this should provide input for the question if the project activities are on the right path to a positive return on investment. The suggested approach was tested in a research project on intelligent cargo solutions with different pilot scenarios.
\end{abstract}

Keywords: Collaborative process, assessment, value proposition, collaboration capability.

\section{Introduction}

Development work is an investment. Only if the output of this work generates adequate value for its customers there is a chance for a positive return on investment. For example, it is not enough that a new software-tool provides "fancy" new features. It is important that these features reduce, facilitate, accelerate or qualitatively improve the customer's work so that he can reduce cost or generate higher revenues. The value is determined by the difference between those benefits and the liabilities, in particular the price, the implementation costs, and the maintenance costs [1]. Only in case of a 
positive value the costumer would be willing to buy the new tool and implement it. So, in addition to the potential market volume (number of potential customers) a concrete value proposition is an essential prerequisite for market success of newly developed products [1], [2], [3], [4], [5].

To increase the likelihood of a positive return on investment it is necessary to compare the expected development cost with the potential market volume and the benefits the customers could obtain from the new product. This should already be done in the early development phases to avoid that resources are used for concepts that do not fulfill the requirements for market success. Therefore the project has to gain a sound understanding of the mechanisms of value generation for potential customers. However, this is difficult when only very rough specifications are available (e.g. in the early development phases) and there are only few or no experiences from existing products in particular for highly innovative products that should be "pushed" into the market. This difficulty is even amplified if the new product is developed for very dynamic markets since there is no time for extensive analysis after a first rough specification of the product.

In many development projects the initiating companies involve other partners, in particular suppliers, research institutes and costumers, for additional competencies, resources and experiences. Due to the uncertainties and the required creativity this involvement is usually no standard customer-suppliers relationship with precisely defined deliverables and payments. Rather it can be regarded as collaboration [6] where the partners contribute to a common goal in a more or less non-hierarchic way. Thus, there is a need for a collaborative process to assess the potential value generation on the side of potential customers (also called "customer value" [2]). The general approach in this paper to accomplish this objective is to identify a suitable existing approach for assessing customer value and adapt it if necessary for a collaborative process in the early development phases. In the second step the required collaboration structure and corresponding interactions for this process will be described. Finally it will be analyzed what requirements upon the collaboration capabilities are caused by the suggested process. The considerations are based on the practical application in a research project on intelligent cargo solution with different pilot scenarios.

\section{Assessment of Potential Value Generation on Customer Side}

As described above the objective of the assessment process is to enable a rough estimation of the value that the potential customer could obtain from the new solution. The customer value is determined by the gained benefits minus the liabilities the customer has to take for applying the solution. Taking the example of new intelligent cargo solutions the benefit could be reduced labor costs due to a higher degree of automation. On the liability side the price for hard- and software as well as the implementation costs, e.g. for setting up the system and creating interfaces to existing systems, have to be regarded. The question is how to come to a conclusion regarding the benefits and their significance? The following aspects have to be taken into consideration:

- The assessment will start in the very early phases of the development project with many uncertainties. So there is only a low level of specification 
available for the future product. In addition the effort of the assessment has to be low since it is not sure that the development will produce a return on investment.

- Most likely there will be a parallelism of the assessment and the ongoing development work to ensure short development cycles. Consequently it will be necessary to update the assessment according to the progress of development (dynamic process).

- If the project is dealing with very innovative ideas there is usually a gap between these ideas and the practical user problems. In some cases entire processes become obsolete and are replaced by new ones.

- The new product can often be used in different application domains. This means that several specific mechanisms of value generation in different application scenarios have to be considered. In addition it is necessary to make results comparable to draw generic conclusions that are also adequate for other application scenarios.

- The involved partners are generally independent, so they cannot be "forced" to contribute (beyond contractual obligations, if there is a contract at all). So it is necessary to convince partners and to reach consensus and common agreements.

Regarding these conditions it has to be analyzed if there are already suitable approaches to assess value generation on the customer side.

Since the objective is to do this assessment in the early development phases it was analyzed first if there are approaches in the corresponding models for development processes that are provided by research in particular for ICT solutions. Some well known examples for these process models are the Stage Gate approach [7] the so called "Waterfall Model" [8], the Spiral Model [9], the V-Model [10] or IBM's Rational Unified Process - RUP [11], or the Microsoft Solution Framework [12]. However, although some of these models, e.g. the Stage Gate approach or the Microsoft Solution Framework, mention explicitly the business aspect and the fulfillment of customers' requirements, there is no concrete suggestion for the assessment of value proposition.

Another research domain that is engaged in considerations on customer value and could be a source for assessment approaches is the domain of business models. A business model represents a way to express the logic of how a company is earning money [13] and value proposition is regarded as a key element of a business model [4], [3], [5]. Business Models (or Business Plans) are usually prepared when a new business should be established and investors have to be informed about the quality of the business. So they consider the customer value in a very early stage. In addition they consider in most cases all relevant application domains to demonstrate the market potential. However, business models are usually built upon a clearly specified future product and an assumed price for this product, while they take a more generic view on the customer value generation (it is assumed that the customer has a need for this product). These approaches for business models do not provide a method to analyze the potential value generation.

A more specific view on the value generation is provided by approaches for so called "Business Cases" (sometimes also called project charters) [14], [15], [16]. 
They are usually used inside an organization to convince the potential sponsors to support a defined improvement project, e.g. the implementation of RFID readers in a warehouse. Most approaches for business cases describe the problem / opportunity for improvements, the project scope, the approach for solutions, objectives regarding the improvements, and the relation between costs and benefits. This provides the necessary information to the sponsors. An approach that describes the mechanisms of value generation in a causal chain from changing process parameters to business effects is provided by Kapadia et al. [17]. The basic idea is to analyze which process parameters can be controlled directly by the organization (Process X) and then evaluate the impact that certain changes in the process parameters have on the overall process performance (Process $\mathrm{Y}$ as a function of Process $\mathrm{X}$ ) and finally on the costs and revenues (Business Y).

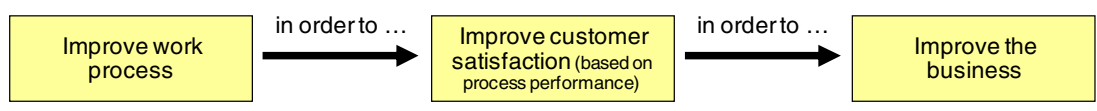

Fig. 1. Causal chain from improving process work to business effects [16]

Since these types of business cases are very specific for a particular company / organization they generally do not provide generic conclusions for the value generation in a whole application domain or even in different application domains. In addition, business cases are often not driven by innovation. They are looking for the best solution for a certain problem / improvement opportunity instead of looking for potential application opportunities for new innovative solutions. Summarized this means that a business case approach could provide a good understanding of the mechanisms of value generation on the customer side. In particular the approach of Kapadia et al. describes this mechanism in a structured way. However, it is necessary to go beyond the level of a single company / organization to enable an assessment that is sufficient for a development project. Therefore the business case approach should be combined with a business model view that considers different groups or types of customers in different application domains. Exemplary business cases at different pilot customers from the most relevant application scenarios will lead to general conclusions regarding the potential generation of customer value. For the development of innovative products it is important to identify customers that are market leader and ahead in their field. Hippel [18] suggested an approach to identify those so called Lead Users.

\section{Methodological Approach for Collaborative Value Assessment}

The assessment of the customer value that a new product can generate requires a relation between the capabilities of the product and a business case on the customer's side. This relationship is illustrated in the picture below (Figure 2).

On the customer's side the value generation is described according to the business case approach from Kapadia et al. It is assumed that the application of the new product has an impact on certain parameters of a customer's process, e.g. the acceleration of process steps. This should have a positive impact on the overall process performance 
that is received by the end customers or stakeholders, e.g. an improved on-time delivery. The improved process performance should lead to less cost, e.g. fewer penalties due to late delivery, or increased revenues from satisfied customers.

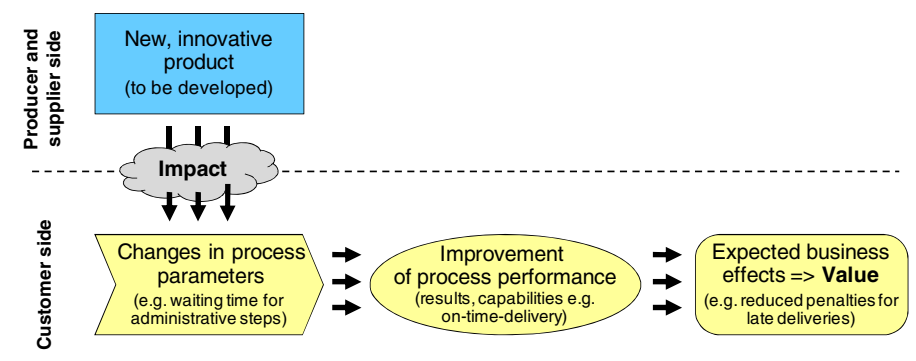

Fig. 2. Link between the product to be developed and the business case

It is important to look at the entire chain from product capabilities to business effect, since there is no value in changing certain process parameters if this does not lead to a significant business effect. If for example a product can increase the frequency of providing tracking and tracing information during a transport but the final customer does not need such detailed information and there is also no cost reduction, then there is no real value in this product capability. It is essential to analyze if the new product has an impact on current problems of the customer (cost, time, quality) or if the product can support fundamentally new processes with new revenues. Therefore, one of the first steps is to ask typical customers in the different application domains if they can see rooms for improvement in their processes regarding the new solution or if there are even already identified problems ("where are we losing money") that could be addressed by it. Based on these first ideas the whole causal chain from impact on process parameters to business effects has to be described and analyzed to assess if the potential value is relevant.

One challenge in this analysis is the specification of the new product that is needed to assess its potential impact on process parameters. Therefore it is important to achieve a rough first understanding of the product's future capabilities already in the very early development phases. Probably the considerations on the business cases will provide a feedback to the development work when additional requirements upon the new product become apparent.

The described analysis has to be done not only for one business case but for several business cases in different application domains. This provides an input for the assessment of the overall potential that is required for the business model. The different analyses are shown in the lower part of Figure 3.

How to get the necessary information to do this analysis? The producer has usually not such a deep understanding of the processes on the customers' side. In addition, at least for complex innovative products he needs information from his suppliers to draw up a first rough specification. Sometimes the suppliers even need information about customer requirements upon the new product to provide their input for the specification. So the assessment requires the involvement of different partners. Since these partners are generally independent and have not yet a hierarchic relationship the 
assessment can be regarded as a collaboration subject (or a collaboration opportunity). The producer, his suppliers and the selected pilot customers build up a Collaborative Network Organization (CNO) [6] as shown in the graphic below (Figure 3).

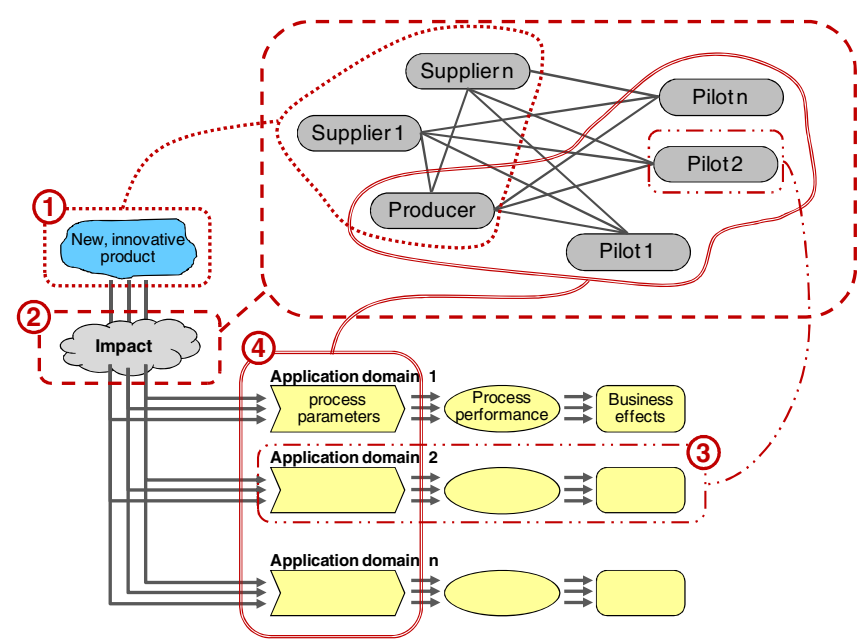

Fig. 3. Collaboration to assess potential value generation for different business cases

As a starting point (collaboration \#1 in Figure 3) the new product has to be specified by the producer in collaboration with his suppliers since the capabilities of new solutions in most cases also depend on the development work of the suppliers. The assessment of the potential impacts requires coordinated contributions from all partners (\#2). Based on the first specifications the pilot customers come up with first ideas for process improvements that can be achieved by applying the new solution. The developing partners have to check if the assumptions of the customers fit and if their requirements could be fulfilled by the new solution. Thus there are feed-back cycles to verify the application scenarios. The particular business cases are mainly drawn up by the corresponding pilot customer (\#3). All pilots together can support the producer to generalize results to come to conclusions that are not only pilot-specific (\#4).

\section{Practical Application and Required Collaboration Capabilities}

The suggested assessment approach was applied in the EURIDICE research project on Intelligent Cargo Solutions that support the interaction of individual cargo items with other cargo items and the surrounding environment. The objective is to improve the logistic performance of in the daily business of operators and industrial users [see www.euridice-project.eu]. The project, funded by the EU, is a collaboration of different companies that are developing technical solutions, research institutes, and pilot customers from different application domains. The single steps that were used to identify the mechanisms of value generation and corresponding assessment criteria at the different partners were already described in an earlier paper [19]. Here the focus 
should be directed towards the aspect of collaboration of the different partners. The required collaboration capability is analyzed according to different aspects of collaboration performance [20], in particular communication, reliability, promptness/speed, flexibility as well as elements of commitment like trust building and information sharing.

First, all partners need a strong ability to communicate, since it is important that the pilot customers understand the potential capabilities of the new product to identify relations to their own processes. On the other side, it is also important for the developers to understand the mechanism of value generation on the customers' side to obtain input for further improvement of the development. Finally it is important to reach a common understanding regarding the assessment criteria and performance indicators to obtain results that are usable for a general assessment.

Flexibility, reliability and promptness/speed are other important collaboration capabilities that are required. Development is usually a time-critical work with a lot of uncertainties and there are strong dependencies between different activities. Therefore it is important that the partners can react flexible on changes (e.g. adaption to new product functionalities) and provide their contribution in a short time according to deadlines.

The coordinator of this collaboration must be capable of trust building, since the all partners provide confidential data (technical approaches, internal processes and problems), in particular have other business relations or act as competitors in the market. Only if the partners trust each other they will be effective in information sharing, which means that relevant information is provided to the other partners without delay. An important capability for the identification of the impact that the solution could have on the process parameters is to give impulses. Only if new ideas are triggered and generated, the development will produce innovative solutions with a high potential. Other aspects like decision synchronization, problem solving, sharing benefits, cost and risks are less important in this early phase, since the objective is just to provide a rough assessment of the potential value proposition. All this is required for understanding of the future mechanisms of value generation and for avoiding unnecessary work.

\section{Conclusions}

The practical application has shown that it is important for the development of new products to understand if and how the customers could gain a specific value from the product. The suggested method provides a guideline for the involved partners to do a first rough assessment of the potential value assessment and it becomes obvious that some functions of the new solutions have a much higher potential for cost reductions and new revenues than others in different application domains. However, the method requires intensive collaboration between the partners. Therefore it has to be assessed if there are partners that can provide the required collaboration capabilities before this method is chosen. The suggested method is designed for the assessment of specific functional capabilities that have an impact on processes. For non-functional features, like prestige, the potential value has to be assessed in a different way. Further research is required for a methodological approach to determine profiles of collaboration requirements in a case specific way and train the partners on this process. 


\section{References}

1. Yang, K., El Haik, B.S.: Design for Six Sigma - A Roadmap for Product Development, pp. 58-61. McGraw-Hill, New York (2003)

2. Woodruff, R.B.: Customer value: The next source for competitive advantage. Journal of the Academy of Marketing Science 25(2), 139-153 (1997)

3. Mahadevan, B.: Business models for Internet-based e-Commerce: An anatomy. California Management Review 42(4), 55-69 (2000)

4. Afuah, A., Tucci, C.L.: Internet business models and strategies: Text and cases, p. 45. McGraw-Hill Irwin, Boston (2001)

5. Elliot, S.: Research model and theoretical implications. In: Elliot, S. (ed.) Electronic Commerce: B2C strategies and models, pp. 291-325. John Wiley, Chichester (2002)

6. Camarinha-Matos, L.M., Afsarmanesh, H.: Collaborative Networks: Reference Modeling, pp. 52-56. Springer, New York (2008)

7. Cooper, R.G.: Stage-Gate Systems: A New Tool for Managing New Products. Business Horizons, 44-54 (May-June 1990)

8. Royce, W.W.: Managing the Development of Large Software Systems. In: Proceedings 9th Conference on Software Engineering, pp. 328-338. IEEE Computer Society, Los Alamitos (1987); Reprinted from Proceedings, IEEE WESCON, pp. 1-9 (1970)

9. Boehm, B.: A Spiral Model of Software Development and Enhancement. Computer 21(5), 61-72 (1988)

10. IABG: The V-Model Development Standard for IT-Systems of the Federal Republic of Germany (1997), http: / / www . v-modell.iabg . de

11. Rational Software Corporation: Rational Unified Process - Best Practices for Software Development Teams. White Paper. Cupertino, USA (1998)

12. Versteegen, G. (ed.), Dietrich, M., Reckert, H., Salomon, K.: Risikomanagement in ITProjekten, p. 198. Springer, Heidelberg (2003)

13. Osterwalder, A.: The business model ontology - a proposition in a design science approach. PhD Thesis, University of Lausanne, p. 15 (2004)

14. Harmon, P.: Business Process Change - A guide for business Managers and BPM and Six Sigma Professionals. Morgan Kaufman Publishers, Burlington (2007)

15. CTG, Center for Technology in Government: Making Smart IT Choices: Understanding Value and Risk in Government IT Investments (2003),

http: / / www.ctg.albany.edu

16. Toutenburg, H., Knöfel, P.: Six Sigma - Methoden und Statistik für die Praxis. Springer, Heidelberg (2008)

17. Kapadia, M.M., Hemanth, S., Sharda, B.: Six Sigma: The Critical Link between Process Improvements and Business Results. American Society for Quality (2003)

18. von Hippel, E.: Lead Users: A Source of novel product concepts. Management Science 32(7), 791-805 (1986)

19. Westphal, I., Vedovato, D., Kalaboukas, K., Bolic, T.: Business Case Driven Assessment of Effects Gained by Intelligent Cargo Objects. In: Cunningham, P., Cunningham, M. (eds.) eChallenges e-2009 Conference Proceedings, IIMC (2009)

20. Westphal, I., Thoben, K.-D., Seifert, M.: Managing collaboration performance to govern virtual organizations. Journal of Intelligent Manufacturing (2008), doi:10.1007/s10845008-0182-5 